\title{
Karakteristik Noise Pada Blower Ring Karena Pengaruh Pembebanan
}

\author{
Parno Raharjo \\ Jurusan Teknik Mesin Politeknik Negeri Bandung \\ E-mail: parno_raharjo@polban.ac.id \\ Diterima: 04-12-2019; Direvisi: 20-12-2019; Dipublikasi: 31-12-2019
}

\begin{abstract}
Abstrak
Blowerring adalah mesin yang berfungsi untuk penyedia udara yang digunakan di berbagai industri. Mesin ini merupakan mesin pembantu utama produksi, sehingga apabila terjadi gangguan akan mengakibatkan berhentinya produksi dan dapat menimbulkan kerugian besar. Agar mesin tersebut tidak terjadi gangguan secara tiba tiba diperlukan pemeliharaan prediktif. Salah satu teknik yang dapat digunakan untuk menentukan kondisi mesin agar tidak terjadi gangguan tiba tiba adalah inspeksi noise. Noise pada mesin yang tidak biasanya menunjukkan adanya gangguan pada mesin tersebut. Inspeksi noise untuk maksud keselamatan kerja sudah lama diaplikasikan, sedangkan informasi mengenai inspeksi noise untuk menentukan kondisi mesin masih minim, sehingga diperlukan kajian yang lebih jauh. Tujuan pada penelitian ini adalah untuk mengetahui karakteristik noise pada blowerring sehingga dapat digunakan sebagai panduan untuk menentukan kondisi blower secara umum. Obyek penelitian adalah blower ring. Pengukuran dan pengambilan data dilakukan dengan menggunakan mikropon yang dilengkapi dengan sistem data akuisisi. Analisa amplitude, time domain, frequency domain dengan menggunakan Mathlab ${ }^{T M}$ digunakan untuk mengetahui karakteristik noise pada blower ringkarena perubahan beban. Hasil pengujian menunjukkan bahwa terjadi impuls pada blower ring. Terdapat korelasi positif antara perubahan beban dan amplitudo noise RMS dan Peak. Pada spektrum menunjukkan terjadinya noise random. Amplitudo yang konsisten meningkat karena perubahan beban terjadi pada frekuensi $102 \mathrm{~Hz}$ (3ff) dan $315 \mathrm{~Hz}$ (10 ff).
\end{abstract}

Kata kunci: amplitude; blower ring; frequency domain; noise; time domain

\begin{abstract}
Blowerring is a machine that serves to provide air used in various industries. This machine is the main auxiliary machine for production, so that if there is a disruption will result in the cessation of production and can cause great losses. So that the engine does not occur suddenly, a predictive maintenance is required. One technique that can be used to determine the condition of a machine to prevent sudden disturbances is noise inspection. Noise on the engine that does not usually indicate interference with the engine. Noise inspection for safety purposes has long been applied, while information on noise inspection to determine machine conditions is still minimal, so further studies are needed. The purpose of this study is to determine the noise characteristics of the blowerring so that it can be used as a guide to determine the condition of blowers in general. The object of research is the blower ring. Measurement and retrieval of data is carried out using a microphone equipped with a data acquisition system. Analysis of amplitude, time domain, frequency domain using MathlabTM is used to determine the noise characteristics of the blower due to load changes. The test results indicate that an impulse occurs in the blower ring. There is a positive correlation between load changes and the amplitude of RMS and Peak noise. The spectrum shows the occurrence of random noise. A consistent amplitude increases because load changes occur at frequencies of 102 $\mathrm{Hz}(3 \mathrm{ff})$ and $315 \mathrm{~Hz}(10 \mathrm{ff})$.
\end{abstract}

Keywords: amplitude; blower ring; frequency domain; noise; time domain

\section{Pendahuluan}

Blowerring merupakan peralatan atau mesinutilitas yang menyediakan udara bertekanan. Mesin ini digunakan pada industri proses dan manufaktur. Bloweradalah mesin pembantu utama produksi, sehingga apabila terjadi gangguanberakibat berhentinya produksi dan dapat menimbulkan kerugian beasr. Agar mesin tersebut tidak mengalami gangguan secara tiba tiba diperlukan penerapan predictive maintenance. Predictive maintenance yang dapat diterapkan untuk menentukan kondisi blowerring adalah inspeksi noise. Noise pada mesin yang tidak biasanya menunjukkan adanya gangguan pada mesin tersebut. Referensi dan informasi mengenai inspeksi noise untuk menentukan kondisi mesin masih minim, sehingga diperlukan kajian yang lebih mendalam. Tujuan pada penelitian ini adalah untuk mengetahui karakteristik noise pada blowerring sehingga dapat digunakan sebagai panduan untuk menentukan kondisi blower secara umum. Noise pada mesin dapat terjadi karena berbagai kondisi antara lain pengaruh beban dan 
kecepatan, serta gangguan komponen. Pada kesempatan ini akan dikaji dan diteliti mengenai karakteristik noise blowerring karena variasi beban.

Inspeksi noise merupakan teknik pemeliharaan prediktif yang bertujuan untuk menentukan kondisi mesin atau peralatan dengan cara menginspeksi kondisi noise yang terjadi pada mesin tersebut. Inspeksi noise telah dilakukan oleh beberapa peneliti, namun demikian informasi masih terbatas, belum mapan dan masih diperlukan penelitian lebih lanjut. Metwally dkk [1] melakukan penelitian yang bertujuan untuk menentukan karakteristik noise pada AC kendaraan terhadap kenyamanan penumpang. Ramroop dkk [2] menerapkan inspeksi kondisi sistem kotak roda gigi dengan menggunakan airborneacoustic yang menghasilkan bahwa inspeksi kondisi akustik memiliki kelebihan jika dibandingkan dengan metode getaran yaitu signal randomnya lebih sedikit. Bayidar dkk [3] melakukan studi perbandingan antara inspeksi getaran dan noise dalam rangka mendeteksi gangguan roda gigi, hasilnya menunjukkan bahwa noise dapat digunakan untuk mendeteksi gear crack, localized wear dan broken tooth pada roda gigi. Cook [4] melakukan inspeksi mesin perkakas melalui pengukurannoise. Hasilnya menunjukkan bahwa terdapat korelasi positif antara keausan cutting tool dengan sinyal noise pada mesin perkakas. Raharjo dkk [5] telah melakukan studi perbandingan inspeksi kondisi bantalan luncur yang mengalami scratching menggunakan surface vibration, airborne sound dan acoustic emission (AE). Hasilnya menunjukkan bahwa sinyal dan spektrum ke tiga pengukuran dapat membedakan antara bantalan yang normal dengan bantalan yang mengalami scratching. AE menunjukkan sensitivitas yang paling tinggi. Raharjo dkk [6] melakukan pengujian karakteristik noise pada pompa sentrifugal karena perubahan beban secara wireless. Pada pengujian tersebut didapat bahwa semakin tinggi beban semakin tinggi amplitudonya dan perubahan sinyal dan spektrumnya jelas, serta amplitudo tertinggi terletak pada frekuensi $120 \mathrm{~Hz}$ (4ff) dan pada 180 $\mathrm{Hz}$ (6ff). Elkaya dkk. [7] melakukan investigasi masalah kerusakan ventilator dengan menggunakan analisis vibrasi dan noise. Hasil investigasi menunjukkan bahwa noise analysis sangat efektif untuk mendeteksi kemungkinan masalah kerusakan pada sudu dan sistem pelumasan.

Dari berbagai studi di atas noise analysis dapat digunakan untuk mendeteksi gangguan mesin, walaupun demikian karakteristik signal noise dan spectrum noisebelum dapat mengidentifikasi kerusakan dengan baik. Selain dari pada itu karakteristik noise pada blower ring belum ada yang mengkaji. Oleh karena itu masih diperlukan studi karakteristik noise untuk mendeteksi gangguanblower ring secara lebih luas dan lebih intensif. Noise pada peralatan dapat berasal darikomponen mesin yang bergetar. Noise merambat sebagai gelombang melalui lingkungan udara mencapai sensor atau pendengar. Noise adalah variasi tekanan lokal yang bergerak melalui media material pada kecepatan tertentu yang dipengaruhi oleh sifat material itu sendiri [8]. Noise dari permesinan atau mesin rotari dapat berbentuk aerodynamic, electromagnetic dan structural noise. Setiap komponen membangkitkan noise pada spesifik frekuensi yang berhubungan dengan natural frequency [9]. Noise karena getaran timbul dalam benda padat, cair dan gas serta tergantung dari media yang dilaluinya. Jika benda padat digetarkan structure borne sound vibration ditransmisikan ke sekelilingnya yang berupa gas. Konstruksi padat yang bergetar yang kemudian sebagai sumber noise yang menimbulkan airborne sound [10]. Noisedapat dibangkitkan juga oleh gesekann. Gesekan pada dua material yang berbeda dalam gerakan luncur mempengaruhi besarnyanoise dan vibration [11]. Unit noise dinyatakan dalam sound pressure level. Besarnyasound pressure level disingkat menjadi $\mathrm{L}_{\mathrm{p}}$ dalam decibel $(\mathrm{dB})$ lebih besar atau kurang dari sound pressure pembanding $\mathrm{p}_{\mathrm{ref}}[8]$. 


\section{Material dan metodologi}

Penelitian ini menggunakan blower ringSD-40 sebagai obyek yang memiliki debit 2,8 m3/men, tekanan $180 \mathrm{mBar}$ yang digerakkan dengan motor listrik, $0.95 \mathrm{kWatt}$ pada putaran $2760 \mathrm{rpm}$, ELF $50 \mathrm{~Hz}$, jumlah sirip 24 buah yang diinstalasi pada ruangan laboratorium yang tidak terredam. Noise sensor diletakkan di depan ring blower dengan jarak 500mm terhadap motor listrik dan ujung saluran dan $1000 \mathrm{~mm}$ terhadap lantai. Pengujian dilakukan pada frekuensi putaran tetap $30 \mathrm{~Hz}(1800 \mathrm{rpm})$ dengan 5 variasi beban tekanan pada discharge yaitu 10,20,30,40 dan $50 \mathrm{mBar}$. Gambar 1 merupakan instalasi pengujian blower ring. Sedangkan untuk skema pengujian noise ditunjukkan pada Gambar 2.

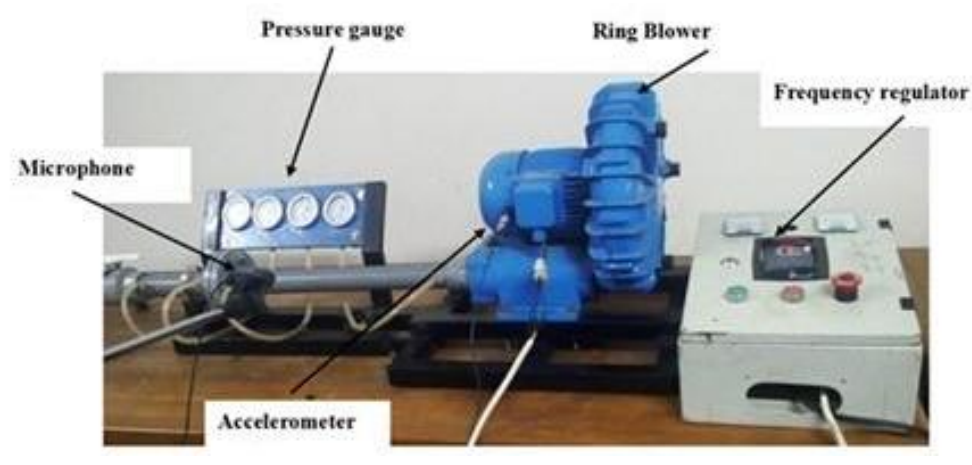

Gambar 1. Instalasi Pengujian Blower Ring

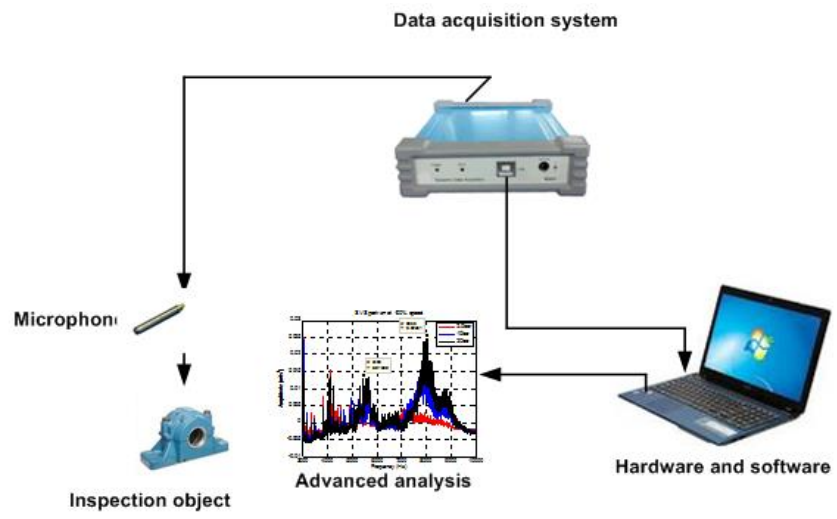

Gambar 2. Skema Pengujian Noise

Instrumentasi pengujian noise menggunakan ICP microphone BAST YG 20107067 dengan sensitivitas 49.5 $\mathrm{mV} / \mathrm{Pa}$ dan frequencyrange 20Hz-100kHz. Data akuisisi yang digunakan Sinocera YE 6231 Dynamic Signal Analyzer 4 Channels dengan sampling rate $96.0 \mathrm{kHz}$. Pengolahan dan penyimpanan data menggunakan software YE 7600 . Untuk melakukan signalanalysis menggunakan MathlabTM. Pengolahan dan analisis data yang dilakukan yaitu analisa amplitude, time domain dan frequency domain.

\section{Hasil dan pembahasan}

Hasil pengujian sinyal noise noise pada blower ring yang dioperasikan pada putaran tetap $30 \mathrm{~Hz}$ (1800 rpm) dengan 5 variasi beban 10, 30 dan $50 \mathrm{mBar}$ ditunjukkan pada Gambar 3. Terlihat menunjukkan pada sinyal noise terjadi impulse dan semakin tinggi tekanannya semakin tinggi amplitudo RMSnya. Gambar 4 menunjukkan Trending amplitudo RMSnya. 


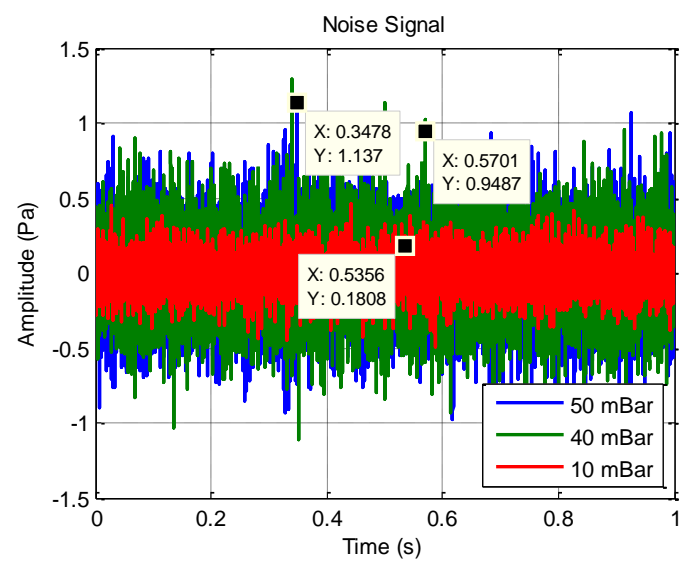

Gambar 3. Sinyal noise pada 10, 40 dan $50 \mathrm{mBar}$

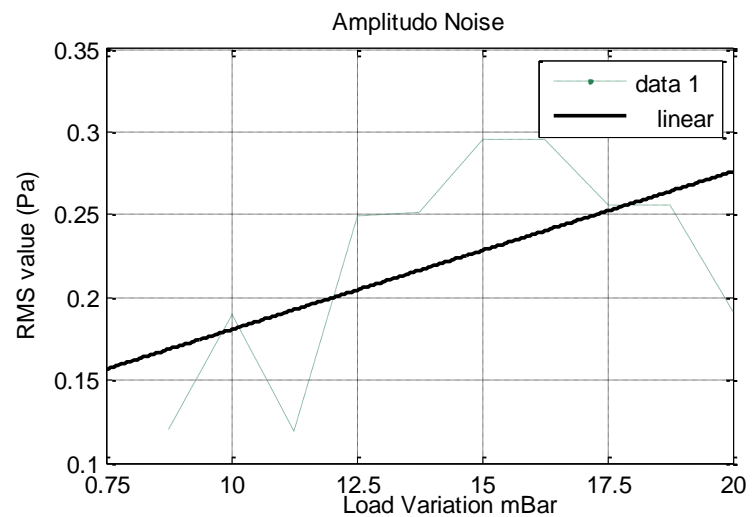

Gambar 4. Trending amplitudo noise RMS

Gambar 5 menunjukkan hasil spektrum noise pengujian noise pada blower ring yang dioperasikan pada putaran tetap $30 \mathrm{~Hz}$ dengan beban 10, 30 dan $50 \mathrm{mBar}$.

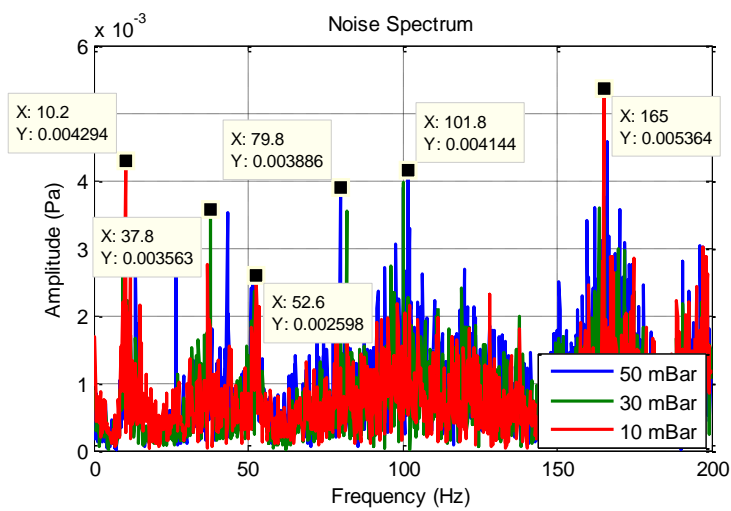

Gambar 5. Spektrum noise pada 10, 30 dan $50 \mathrm{mBar}$, rentang 1-200 Hz

Spektrum noise pada Gambar 5 menunjukkan bahwa semakin tinggi beban semakin tinggi amplitudo noise peaknya. Pada spektrum terjadi noise random. Amplitudo yang konsisten naik karena perubahan beban, terjadi pada frekuensi $102 \mathrm{~Hz}$ (3ff) dan $315 \mathrm{~Hz}$ (10ff), ditunjukkan pada Gambar 6. 


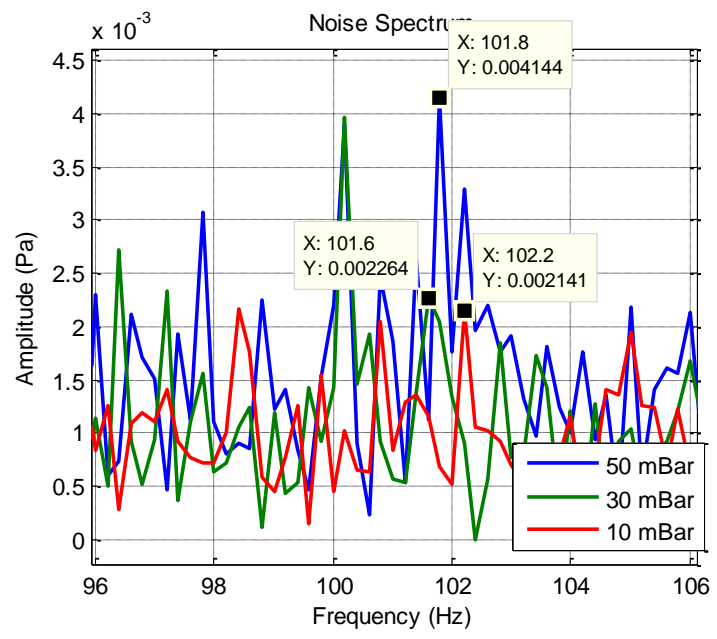

Gambar 6. Frekuensi perubahan beban $96-106 \mathrm{~Hz}$

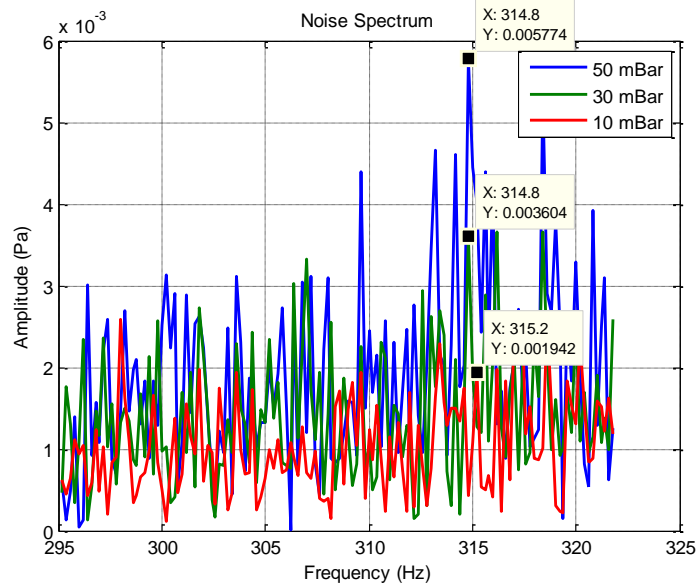

Gambar 7. Frekuensi perubahan beban rentang $295-325 \mathrm{~Hz}$

Trending amplitudo noise peak dengan variasi beban ditunjukkan seperti pada gambar berikut.

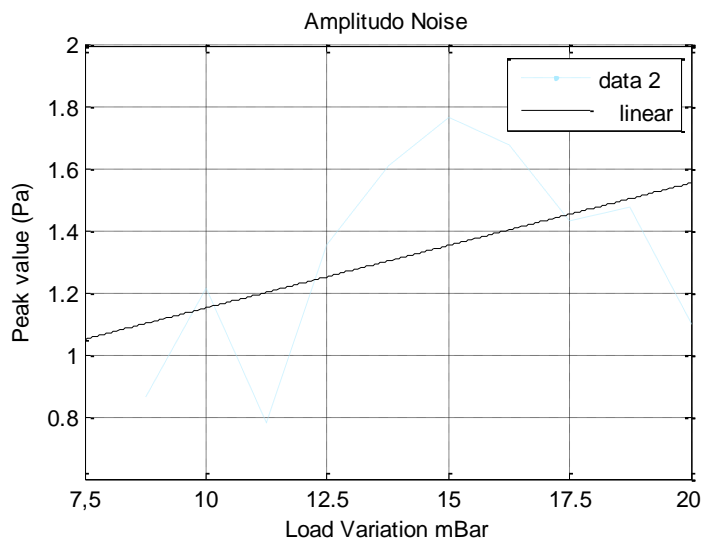

Gambar 8. Trending amplitudo noise peak 
Dari gambar trending amplitudo noise peak mengkonfirmasikan bahwa semakin tinggi beban, maka semakin meningkat juga amplitudo noise peaknya. Noise waterfall dengan empat variasi beban 10, 20, 40 dan 50 mBar nya ditunjukkan seperti pada gambar berikut. Dari gambar Noise Waterfall menunjukkanterjadinya noise signal pada spektrum. Dari uraian di atas dapat disimpulkan bahwa sinyal noise menunjukkan terjadinya impuls yang random. Terdapat korelasi positif antar beban dan amplitudo noise RMS dan Peak.

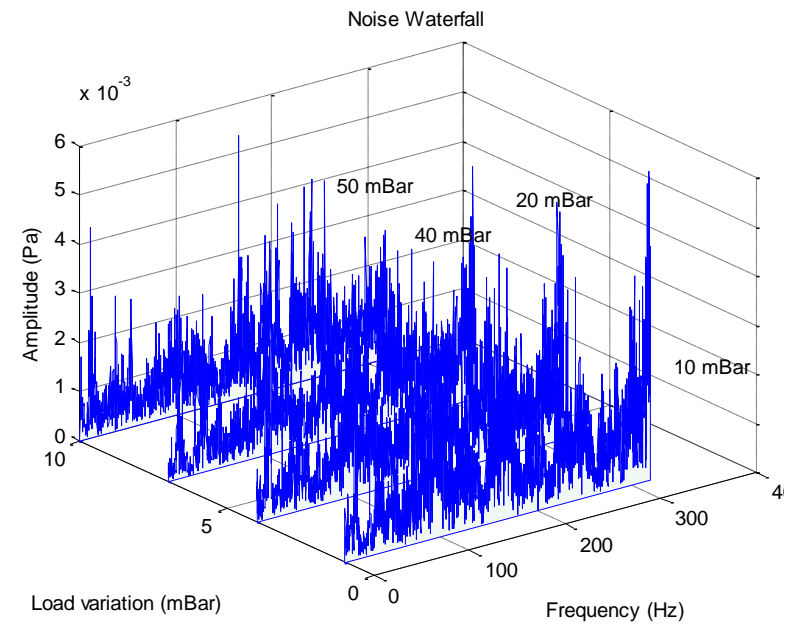

Gambar 9. Noise Waterfall rentang 1-200 H

\section{Kesimpulan}

Dari percobaan dan analisa pengujian noise pada blower ring karena perubahan beban dapat disimpulkan bahwa pada pengujian noise blower ring karena perubahan beban terjadi impuls. Terdapat korelasi positif antara perubahan beban dengan amplitudo noise RMS dan Peak. Pada spektrum menunjukkan terjadi nois random. Kenaikan amplitudo konsisten meningkat karena perubahan beban, terjadi pada frekuensi $100.1 \mathrm{~Hz}$ (3ff) dan $315 \mathrm{~Hz}$ (10 ff).

\section{Daftar Pustaka}

[1] Metwally S. M., Khalil M. I., Abouel Seoud S. A. Noise Evaluation of Automotive AC Compressor, International Journal of Energy and Environtment. 2011; Volume 2, Issue 3, pp. 505-515.

[2] Ramroop, G., Liu, K, Gu, F, Payne S, Ball A. D, Airborne Acoustic Condition Inspections of a Gearbox System, Electronic Proceeding of the $5^{\text {th }}$ Annual Maintenance and Reliability Conference, Gatlinburg, Tennessee, USA, May 2001.

[3] Baydar, N., Ball, A. Case History, A Comparative Study of Acoustic and Vibration Signal in Detection of Gear Failures using Wigner-Ville Distribution, Mechanical System and Signal Processing, Academic Press. 2001, pp. 1091-1107.

[4] Cook, V., G. Acoustic Inspections of Machine Tool Health Using Transmitted Sound, Proceeding of International Conference on Industrial Engineering and Operation Management ; 3-6. 2012 ; Istambul, Turkey. 2012. pp. 18311839.

[5] Raharjo, P, Tesfa, B, Gu, F dan Ball, A, D. Comparative Study of the Inspections of a Self Aligning Spherical Journal Bearing using Surface Vibration, Airborne Sound and Acoustic Emission, $25^{\text {th }}$ International Congress on 
Condition Inspections and Diagnostic Engineering, IOP Publishing Journal of Physics Conference Series 364. 2012.

[6] Raharjo, P., Sofyan, Y., Maariz, T. Karakteristik Noise Nirkabel Pada Pompa Sentrifugal Karena Perubahan Beban, Jurnal Rekayasa Mesin. 2017 ; Vol. 12, No. 3, Hal. 95-102.

[7] Erkaya, S., Ulus, S. Investigation of Fan Foults Problems Using Vibration and Noise Analysis, 19th Annual Building Services, Mechanical and Building Industry Days, International Conference; 10-11 October 2013, Debrecen, Hungary.

[8] Barron, F. Industrial Noise Control and Acoustic, Marcel Dekker Inc, New York. 2003.

[9] Kim, M., Jang, G., Lee, C., dan Lim, D. Experimental Identification of Abnormal Noise and Vibration in a High Speed Polygon Mirror Scanner Motor due to Mechanical Contact of Plain Journal Bearing, Springer Verlag, Microsystem Technology 16. 2010.

[10] Schenk, C., Machine Diagnosis. Methods and Instruments for Analysing Machine Condition and for Early Recognition of Machine using Vibration Measurement, Serie 40.

[11] Rorrer, R. and Juneja. V. Friction Induced Vibration and Noise Generation of Instrument Panel Material Pair. Elseiver. Tribology International. 2002 ; No. 35, pp. 523-531. 